\title{
RESPON BIBIT SURIAN (Toona sinensis (Juss,) M. Roem.) TERHADAP INOKULASI BEBERAPA DOSIS FUNGI MIKORIZA ARBUSKULA PADA MEDIA TANAH ULTISOL YANG DICAMPUR PUPUK KOMPOS
}

\author{
RESPONSE OF SURIAN SEED (Toona sinensis (JuSS.) M. Roem.) OF \\ INOCULATION OF SOME DOSAGES ARBUSCULAR MYCORRHIZAL FUNGI ON MEDIA ULTISOL \\ MIXED WITH COMPOST
}

\author{
Feby Zulya*, Zozy Aneloi Noli, Tesri Maideliza \\ Laboratorium Riset Fisiologi Tumbuhan, Jurusan Biologi, FMIPA, Universitas Andalas
}

*Corresponding author: febyzulya@gmail.com

Diterima: 12 Desember 2015. Direvisi: 20 Februari 2016. Disetujui: 26 Februari 2016.

\begin{abstract}
Abstrak
Penelitian tentang pertumbuhan bibit surian (Toona sinensis (Juss,) M. Roem pada tanah ultisol yang dicampur pupuk kompos dengan penambahan Fungi Mikoriza Arbuskula (FMA) telah dilakukan pada bulan November 2014 sampai April 2015 di Rumah Kaca dan Laboratorium Fisiologi Tumbuhan, Jurusan Biologi, Fakultas Matematika dan Ilmu Pengetahuan Alam, Universitas Andalas, Padang. Penelitian ini bertujuan untuk mengetahui pertumbuhan bibit surian pada media tanah ultisol yang dicampur pupuk kompos dengan penambahan FMA. Penelitian ini menggunakan metode Rancangan Acak Lengkap (RAL) dengan 4 perlakuan dan 6 ulangan. Perlakuannya adalah tanpa inokulasi (hanya pupuk organik), $5 \mathrm{~g}$ inokulan per tanaman, $10 \mathrm{~g}$ inokulan per tanaman, $15 \mathrm{~g}$ inokulan per tanaman. Hasil penelitian menunjukkan bahwa pertumbuhan bibit surian pada media tanah ultisol yang dicampur pupuk kompos dengan penambahan FMA memberikan pengaruh nyata terhadap pertambahan diameter batang.
\end{abstract}

Kata kunci: Fungi Mikorhiza Arbuskular; Kompos; Toona sinensis

\begin{abstract}
Study on the seedling growth of surian inoculated with some doses of Arbuscular Mycorrhizal Fungi (AMF) on ultisol mixed compost has been conducted from November 2014 until February 2015 in the Greenhouse and Plant Physiology Laboratory, Department of Biology, Faculty of Mathematics and Natural Sciences, Andalas University, Padang. The aim of this study was to find the growth of surian seedling that inoculated with some dosages of AMF on ultisol mixed compost. The study used a Completely Randomized Design with four treatments and six replications. The treatments were done without inoculation, $5 \mathrm{~g}$ inoculants/ plant, $10 \mathrm{~g}$ inoculants/ plant, $15 \mathrm{~g}$ inoculants/ plant. Result of this study indicated that AMF given on ultisol soil gave significant effect on increasing stem diameter of surian seedlings.
\end{abstract}

Keywords: Arbuscular Mycorrhizal Fungi; Compost; Toona sinensis

Permalink/DOI: http//:dx.doi.org/10.15408/kauniyah.v9i1.3253 


\section{PENDAHULUAN}

Persediaan dan permintaan hasil kayu yang merupakan bahan baku untuk industri perkayuan, seperti kayu lapis, pulp dan kertas semakin berkurang. Keadaan tersebut membuktikan bahwa saat ini hutan alam tak sanggup lagi menyediakan kebutuhan kayu bagi perindustrian Indonesia (Khaeruddin, 1999).

Pemerintah telah menetapkan kebijaksanaan dan mendorong pembangunan hutan tanaman. Pembangunan hutan tanaman penting dilaksanakan, diharapkan dapat meningkatkan produktivitas lahan (Samsudi, 1990). Salah satu alternatif yakni dengan pembangunan Hutan Tanaman Industri (HTI). Pembangunan HTI merupakan investasi besar dengan waktu panen yang cukup lama. Jenis yang dibudidayakan untuk HTI biasanya mempunyai daur tanam minimal 7-10 tahun. Untuk menunjang upaya tersebut, diperlukan bibit tanaman dalam jumlah yang banyak dan pertumbuhan bibit yang baik. Salah satu jenis tanaman yang digunakan untuk HTI yaitu tanaman surian [Toona sinensis (Juss,) M. Roem]. Menurut Yuhernita dan Juniarti (2009) Jenis T. sinensis merupakan tanaman yang cepat tumbuh dan kayu tanaman surian mempunyai harga jual yang tinggi karena dapat digunakan sebagai bahan bangunan, peti, venire, alat musik, kayu lapis, dan mebel.

Klasifikasi tanaman Toona sinensis adalah sebagai berikut: Kingdom: Plantae; Subkingdom: Traceobionta; Superdivisi: Spermatophyta; Divisi: Magnoliophyta; Kelas: Magnoliopsida; Subkelas: Rosidae; Ordo: Sapindales; Famili: Meliaceae; Genus: Toona; Spesies: [Toona sinensis (Juss,) M. Roem].

Untuk mendapatkan tanaman yang berkualitas baik, tanaman harus memiliki kesesuaian antara syarat tumbuh tanaman dengan karakteristik lahan tempat tumbuhnya. Karakteristik lahan yang baik yaitu lahan yang kaya bahan organik dan mempunyai unsur hara yang diperlukan oleh tanaman (Durahim \& Hendromono, 2001). Tanah ultisol merupakan salah satu jenis tanah di Indonesia yaitu mencapai 45.794.000 hektar atau hampir 25\% dari total seluruh daratan Indonesia. Menurut Soepardi (1983), masalah utama yang dihadapi dalam pemanfaatan tanah ultisol adalah kemasaman dan kelarutan aluminium $\left(\mathrm{Al}^{3+}\right)$ yang tinggi dan miskin unsur hara. Namun jika tanah ini dikelola dengan tepat maka produktivitasnya dapat ditingkatkan sehingga bisa produktif.

Menurut Suntoro (2001), penambahan bahan organik pada tanah masam antara lain inseptisol, ultisol dan andisol mampu meningkatkan $\mathrm{pH}$ tanah dan menurunkan $\mathrm{Al}$ tertukar tanah. Selain itu, pemberian pupuk organik dapat meningkatkan aktifitas mikroba tanah baik mikroflora maupun mikrofauna (Farida, 1995). Hal ini disebabkan karena pupuk organik mampu meningkatkan kandungan hara di dalam tanah sehingga dengan kondisi tanah yang baik dapat merangsang aktivitas mikroba tanah.

Mikroriza merupakan salah satu kelompok mikroorganisme yang berperan membantu penyerapan hara oleh tanaman. Mikoriza merupakan struktur yang terbentuk karena simbiosis mutualisme antara fungi tanah dengan akar tanaman (Subiksa, 2002). Adanya simbiosis mutualistik antara fungi mikoriza dengan perakaran tanaman dapat membantu pertumbuhan tanaman menjadi lebih baik.

Beberapa penelitian sebelumnya yaitu oleh Suherman, Anne dan Santi (2006) mendapatkan penambahan FMA 10g/tanaman adalah yang paling optimal dalam pertumbuhan kelapa sawit (Elaeis guineensis). Tirta (2006) mendapatkan dosis terbaik penggunaan FMA yaitu sebanyak $20 \mathrm{~g} / \mathrm{tanaman}$ pada bibit panili. Pentingnya keberadaan Toona sinensis terutama untuk mendukung usaha rehabilitasi hutan (Samsudi, 1990), perbaikan lingkungan dan peningkatan produksi kayu maka penelitian ini sangat perlu dilakukan untuk dapat mengetahui pengaruh pertumbuhan bibit surian [Toona sinensis (juss,) M. Roem] pada media tanah ultisol yang dicampur pupuk kompos dengan penambahan FMA. Tujuan dari penelitian ini adalah untuk mengetahui partumbuhan bibit surian [Toona sinensis (juss,) $\mathrm{M}$. Roem] pada media tanah ultisol yang dicampur pupuk kompos dengan penambahan FMA. 


\section{MATERIAL DAN METODE Rancangan Penelitian}

Penelitian ini dilakukan dengan metode eksperimen memakai Rancangan Acak Lengkap (RAL) dengan 4 perlakuan dan 6 ulangan. Perlakuan yang diberikan berupa dosis inokulan FMA pada media tanah ultisol yang dicampur pupuk kompos sebagai berikut: $\mathrm{A}=$ tanpa FMA (Kontrol); $\mathrm{B}=5 \mathrm{~g} /$ tanaman; $\mathrm{C}=$ $10 \mathrm{~g} /$ tanaman; $\mathrm{D}=15 \mathrm{~g} /$ tanaman.

\section{Persiapan Media Tanam}

Media tanam yang digunakan pada penelitian adalah tanah ultisol dan pupuk kompos yang di dapatkan dari Laboratorium Tanah, Jurusan Ilmu Tanah, Fakultas Pertanian, Universitas Andalas. Tanah ultisol terlebih dahulu dibersihkan dari kotoran dengan cara disaring menggunakan ayakan dan disterilisasi menggunakan autoclave. Setelah itu tanah ultisol steril kemudian dicampurkan dengan pupuk kompos dengan perbandingan 1:1 kemudian dimasukkan ke dalam polibag 5 kg sama banyak.

\section{Penyediaan Bibit Surian}

Bibit surian yang digunakan adalah bibit surian yang berumur lima bulan yang diperoleh dari CV. Warna Khara, Suplayer dan Contractor, Lubuk Minturun, Koto Tangah, Padang.

\section{Persiapan Inokulan FMA Indigenous}

Inokulam mikoriza diperoleh dari Seameo Biotrop, Bogor, Indonesia. Untuk menentukan bobot inokulan yang akan diaplikasikan terlebih dahulu dilakukan penghitungan kepadatan spora. Penghitungan dilakukan dengan cara berikut: masing-masing inokulan ditimbang sebanyak $1 \mathrm{~g}$ lalu dimasukan ke dalam saringan bertingkat. Pencucian dilakukan sampai air keluar dari saringan terbawah. Selanjutnya secara bertahap saringan diangkut satu per satu dimulai dari yang paling atas, isi saringan ditampung menggunakan cawan petri terpisah, diamati di bawah mikroskop dan dihitung jumlah sporanya. Setelah dilakukan penghitungan didapatkan kepadatan spora \pm 45 spora/g inokulan.

\section{Perlakuan dan Inokulasi FMA pada Bibit Tanaman}

Inokulasi FMA dilakukan dengan cara mengeluarkan setengah media tanam dari polibag, kemudian bibit tanaman dipindahkan ke media tanam tersebut. Inokulan FMA di sekitar perakaran sesuai dengan perlakuan dan tutup kembali dengan media tanam. Bibit yang telah di tanam diletakkan di rumah kaca. Bibit dipelihara selama 12 minggu.

\section{Pemeliharaan Bibit}

Pemeliharaan bibit meliputi penyiraman dan pengendalian gulma. Penyiraman dilakukan satu kali sehari menggunakan gelas plastik yang telah ditandai dan diberi lubang di bagian bawahnya. Penyiraman dilakukan dengan cara mengisi air sesuai dengan bagian yang telah ditandai, hal ini dilakukan agar banyaknya air sama setiap perlakuan. Selan-jutnya pemberian lubang pada bagian bawah bertujuan agar bibit dalam polybag tidak rusak dan tanah tempat tumbuh tidak padat. Pengendalian gulma dengan mencabut gulma yang tumbuh di sekitar tanaman.

\section{Parameter Pengamatan}

Parameter yang diamati dalam penelitian ini adalah persentase bibit yang hidup, pertambahan tinggi tanaman $(\mathrm{cm})$, pertambahan jumlah helaian daun, pertambahan diameter batang tanaman $(\mathrm{mm})$, bobot kering tanaman, derajat infeksi FMA dan ketergantungan tanaman terhadap mikoriza (mycorrhizal dependency).

\section{Persentase Bibit yang Hidup}

Setelah bibit berumur 12 minggu sejak dipindahkan dari media perlakuan. Persentase bibit dihitung dengan menggunakan rumus: jumlah ulangan x $100 \%$.

\section{Pertambahan Tinggi Tanaman $(\mathrm{cm})$}

Tinggi tanaman diukur dari permukaan tanah sampai pada ujung titik tumbuh. Pengamatan dilakukan sekali seminggu. Pengamatan pertama kali dilakukan saat bibit diberi perlakuan sampai bibit berumur 12 minggu setelah tanam. 


\section{Pertambahan Jumlah Helaian Daun}

Pengukuran pertambahan jumlah daun dilakukan setiap minggu dengan menghitung jumlah daun yang telah membuka sempurna. Pengamatan pertama kali dilakukan saat bibit diberi perlakuan sampai bibit berumur 12 minggu setelah tanam.

\section{Pertambahan Diameter Batang Tanaman}

Pengamatan dilakukan setiap minggu dengan mengukur diameter batang tanaman menggunakan vernier caliper. Pengukuran diameter batang pada $10 \%$ dari tinggi tanaman awal dan diberi tanda. Pengukuran diameter dilakukan setiap minggu pada batang yang telah diberi tanda.

\section{Bobot Kering Tanaman}

Penghitungan bobot kering tanaman dilakukan pada akhir pengamatan. Sampel berat basah tanaman terdiri dari akar, batang dan daun dipotong-potong lalu ditimbang. Potongan dari setiap bagian tanaman dibungkus dengan kertas koran dan dikeringkan menggunakan oven listrik pada suhu $80^{\circ} \mathrm{C}$ selama 2x24 jam kemudian ditimbang berat keringnya.

\section{Derajat Infeksi FMA}

Sampel akar dibersihkan dari tanah yang melekat menggunakan air mengalir. Akar tanaman yang muda diambil dan dipotong $1 \mathrm{~cm}$ untuk masing-masing sampel. Potongan akar dimasukan ke dalam botol film yang berisi larutan $\mathrm{KOH} 10 \%$ sampai terendam dan diinkubasi selama 24 jam. Akar dibilas dengan akuades selanjutnya akar direndam dalam $\mathrm{HCl}$ 2\% selama 30 menit lalu dikeringkan. Potongan akar diberi pewarna staining dan dibiarkan selama 24 jam. Ganti dengan larutan distaining biarkan selama semalam.

Sebanyak 10 potongan akar yang telah diwarnai diambil secara acak dan disusun di atas kaca objek, sampel ditekan dengan cara squash dan diamati di bawah mikroskop. Jumlah akar yang terinfeksi dan yang tidak terinfeksi dicatat dan dihitung untuk mengetahui persentase infeksi. Akar yang terinfeksi ditandai dengan adanya hifa, vesikula atau arbuskula. Derajat infeksi dihitung dengan menggunakan rumus: \% derajat infeksi $=(\Sigma$ akar yang terinfeksi / $\Sigma$ akar yang diamati) $\mathrm{x}$ $100 \%$.

Tabel 1. Kriteria efektifitas derajat infeksi mikoriza (Brundrett et al., 1996)

\begin{tabular}{cc}
\hline Derajat Infeksi $(\%)$ & Kriteria \\
\hline $0-5$ & Sangat rendah \\
$5-25$ & Rendah \\
$25-50$ & Sedang \\
$50-75$ & Tinggi \\
$75-100$ & Sangat tinggi \\
\hline
\end{tabular}

Untuk mengetahui Mycorrhizal dependency dihitung menggunakan rumus: $\mathrm{MD}=[(\mathrm{BK}$ tanaman dengan mikoriza $-\mathrm{BK}$ tanaman tanpa mikoriza) / BK tanaman tanpa mikoriza] x $100 \%$, dengan MD = Mycorrhizal Dependency; $\mathrm{BK}=$ Bobot kering $($ Simarmata et al., 2005).

\section{HASIL}

Berdasarkan penelitian yang telah dilakukan mengenai pertumbuhan bibit surian pada media tanah ultisol dengan campuran pupuk kompos penambahan FMA didapatkan hasil sebagai berikut.

\section{Persentase Bibit Surian yang Hidup}

Persentase bibit surian yang hidup dengan perlakuan inokulasi beberapa dosis FMA pada media tanah ultisol dengan campuran pupuk kompos dapat dilihat pada Tabel 3. Rata-rata pertambahan tinggi tanaman, jumlah daun dan diameter batang bibit surian yang diinokulasi dengan FMA pada media tanah ultisol dengan campuran pupuk kompos disajikan pada Tabel 4. Rata-rata berat 
kering batang dan daun (bagian atas), akar (bagian bawah) dan berat kering total bibit surian yang diinokulasikan dengan beberapa dosis inokulan FMA pada media tanah ultisol dengan campuran pupuk kompos, data lebih jelasnya disajikan pada Tabel 5.
Persentase derajat infeksi FMA pada akar tanaman surian dengan perlakuan beberapa dosis inokulasi FMA pada media tanah ultisol dengan campuran pupuk kompos setelah 12 minggu disajikan pada Tabel 6 .

Tabel 2. Kriteria ketergantungan tanaman terhadap mikoriza (Mycorrhizal dependency) (Habte \& Manjunath, 1991)

\begin{tabular}{cc}
\hline Mycorrhizal Dependency $(\%)$ & Kriteria \\
\hline 75 & Sangat Tinggi \\
$50-75$ & Tinggi \\
$25-50$ & Cukup \\
25 & Kurang \\
0 & Tidak Ketergantungan \\
\hline
\end{tabular}

Tabel 3. Persentase hidup bibit surian setelah 12 minggu yang diinokulasi dengan FMA

\begin{tabular}{cc}
\hline Dosis FMA (g/tanaman) & Persentase bibit yang hidup (\%) \\
\hline 0 & 100 \\
5 & 100 \\
10 & 100 \\
15 & 100 \\
\hline
\end{tabular}

Tabel 4. Rata-rata pertambahan tinggi, jumlah daun dan diameter batang bibit surian yang diinokulasi dengan beberapa dosis selama 12 minggu pengamatan

\begin{tabular}{cccc}
\hline $\begin{array}{c}\text { Dosis FMA } \\
(\mathrm{g} / \text { tanaman })\end{array}$ & $\begin{array}{c}\text { Rata-rata pertambahan } \\
\text { tinggi batang }(\mathrm{cm})\end{array}$ & $\begin{array}{c}\text { Rata-rata pertambahan } \\
\text { jumlah daun (helai) }\end{array}$ & $\begin{array}{c}\text { Rata-rata pertambahan } \varnothing \\
\text { batang }(\mathrm{mm})\end{array}$ \\
\hline 0 & $24,75 \mathrm{a}$ & $6,50 \mathrm{a}$ & $0,65 \mathrm{a}$ \\
5 & $24,33 \mathrm{a}$ & $4,51 \mathrm{a}$ & $0,66 \mathrm{a}$ \\
10 & $34,75 \mathrm{a}$ & $7,49 \mathrm{a}$ & $1,24 \mathrm{~b}$ \\
15 & $37,33 \mathrm{a}$ & $6,65 \mathrm{a}$ & $1,33 \mathrm{~b}$ \\
\hline
\end{tabular}

Keterangan: Perlakuan yang diikuti oleh huruf yang sama pada kolom yang sama, tidak berbeda nyata pada uji DNMRT taraf 5\%

Tabel 5. Rata-rata berat kering (BK) batang dan daun (bagian atas), akar (bagian bawah) serta berat kering total bibit tanaman surian yang diinokulasikan dengan beberapa dosis inokulan FMA setelah 12 minggu pengamatan

\begin{tabular}{cccc}
\hline Dosis FMA (g/tanaman) & $\overline{\mathrm{x}}$ BK batang dan daun $(\mathrm{g})$ & $\overline{\mathrm{x}} \mathrm{BK}$ akar $(\mathrm{g})$ & $\overline{\mathrm{x}} \mathrm{BK}$ total $(\mathrm{g})$ \\
\hline 0 & $4,19 \mathrm{a}$ & $0,57 \mathrm{a}$ & $4,76 \mathrm{a}$ \\
5 & $4,17 \mathrm{a}$ & $0,64 \mathrm{a}$ & $4,81 \mathrm{a}$ \\
10 & $6,50 \mathrm{a}$ & $0,96 \mathrm{a}$ & $7,46 \mathrm{a}$ \\
15 & $6,68 \mathrm{a}$ & $1,00 \mathrm{a}$ & $7,68 \mathrm{a}$ \\
\hline
\end{tabular}

Keterangan: Perlakuan yang diikuti oleh huruf yang sama pada kolom yang sama, tidak berbeda nyata pada uji DNMRT taraf 5\% 
Tabel 6. Persentase derajat infeksi FMA pada akar tanaman surian

\begin{tabular}{ccc}
\hline Dosis FMA (g/tanaman) & Derajat Infeksi $(\%)$ & Kriteria \\
\hline 0 & 30 & Sedang \\
5 & 63 & Tinggi \\
10 & 72 & Tinggi \\
15 & 80 & Sangat Tinggi \\
\hline
\end{tabular}

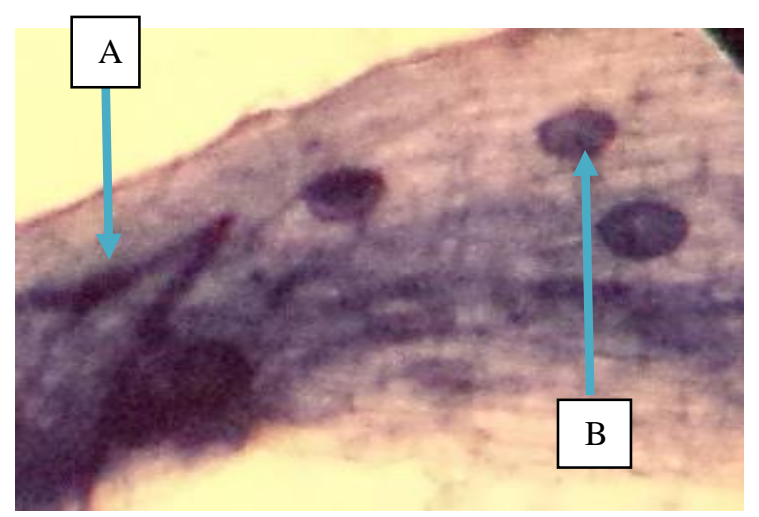

Gambar 1. Bentuk infeksi FMA pada jaringan akar tanaman surian Keterangan: (A) Hifa, (B) Vesikul

\section{PEMBAHASAN}

Persentase bibit tanaman yang hidup pada seluruh perlakuan adalah 100\% (Tabel 3). Pemberian beberapa dosis FMA pada media tanah ultisol dengan campuran pupuk kompos tidak berpengaruh nyata terhadap pertumbuhan bibit tanaman surian. Menurut Omon (2008), pemberian beberapa dosis mikoriza tidak berpengaruh nyata terhadap persentase hidup dua jenis bibit meranti, ditunjukkan oleh persentase hidup bibit tanaman mencapai $75 \%$ pada setiap perlakuan (tanpa diberi mikoriza maupun diberi mikoriza).

Bentuk infeksi FAM pada jaringan akar tanaman surian pemberian beberapa dosis inokulan FMA pada media tanah ultisol dengan campuran pupuk kompos memberikan pengaruh yang tidak berbeda nyata terhadap rata-rata pertambahan tinggi batang dan jumlah daun (Tabel 4). Diduga mikoriza dan pupuk organik tidak berpengaruh terhadap tinggi batang dan jumlah daun. Hal ini kemungkinan disebabkan aktivitas mikoriza dalam meningkatkan penyerapan hara berkurang dengan adanya penggunaan pupuk kompos. Penambahan pupuk kompos akan meningkatkan kandungan $\mathrm{C}$ organik dan ketersediaan P sedangkan peran mikoriza akan berkurang dengan meningkatnya kedua hara tersebut. Kandungan $\mathrm{C}(>2 \%)$ dan $\mathrm{P}$ yang tinggi akan menghambat pertumbuhan hifa propagul, perkecambahan spora dan inisiasi kolonisasi akar (Sarief, 1985).

Pada Tabel 4 didapatkan hasil berbeda nyata terhadap pertambahan diameter batang bibit surian dalam waktu 12 minggu setelah tanam dan dilanjutkan dengan uji lanjut Duncan pada taraf 5\%. Menurut Delvian (2003) dalam hasil penelitiannya mengenai peranan FMA dalam pertumbuhan tanaman Leucaena leucocephala menyatakan bahwa FMA memberikan pengaruh nyata terhadap diameter batang.

Menurut Herdina (2010) pertambahan tinggi batang tanaman lebih dulu terjadi karena pertambahan tinggi batang akan memacu pembelahan sel pada area pucuk yang akan membentuk daun baru. Penggunaan media tanam dengan penambahan pupuk kompos akan semakin meningkatkan partumbuhan vegetatif tanaman. Kandungan unsur hara N, P dan $\mathrm{K}$ yang ada dalam media ini merupakan unsur hara yang penting bagi tanaman terutama nitrogen. Menurut Kononova (1966) nitrogen 
dapat memacu pertumbuhan vegetatif tanaman. Hal ini sejalan dengan hasil penelitian yang ditandai dengan meningkatnya diameter batang.

\section{Berat Kering}

Pemberian beberapa dosis inokulan FMA pada media tanah ultisol dengan campuran pupuk kompos memberikan pengaruh yang tidak berbeda nyata terhadap rata-rata berat kering batang dan daun, berat kering akar dan berat kering total bibit tanaman surian. Hal ini diduga disebabkan oleh FMA yang diinokulasi pada bibit tanaman belum efektif dalam memberi sumbangan hara tanah terhadap bibit tanaman.

Pada Tabel 5 juga dapat dilihat bahwa pemberian mikoriza $15 \mathrm{~g} /$ tanaman dengan penambahan pupuk organik merupakan berat kering tertinggi diantara perlakuan lainnya. Hasil ini sesuai dengan yang dikemukakan oleh Brundret et al., (1966) bahwa pengaruh mikoriza yang paling utama adalah dapat meningkatkan pengambilan unsur fosfat dari tanah dan meningkatkan berat kering. Berat Kering bibit merupakan suatu indikator untuk menentukan baik tidaknya bibit karena berat kering mencerminkan status nutrisi tanaman.

Menurut Prawiranata, Harran dan Tjondronegoro (1981) yang menyatakan bahwa berat kering tanaman mencerminkan nutrisi tanaman karena berat kering tersebut tergantung pada fotosintesis. Pertumbuhan dan pembentukan organ vegeatif tanaman berpengaruh terhadap berat kering. Proses ini sangat dipengaruhi oleh ketersediaan unsur hara bagi tanaman serta laju fotosintesis. Selanjutnya Sarief (1985) mengemukakan bahwa meningkatnya kandungan unsur $\mathrm{P}$ pada bibit akan meningkatkan laju fotosintesis dan merangsang pembentukan daun baru sehingga akan mengakibatkan berat kering bertambah. Berat kering tanaman menunjukkan akumulasi senyawa organik yang berhasil disintesisis tanaman dari senyawa anorganik, terutama $\mathrm{H}_{2} \mathrm{O}$ dan $\mathrm{CO}_{2}$. Unsur hara yang diserap akan memberikan kontribusi terhadap pertambahan berat kering tanaman. Berat kering tanaman merupakan akibat efisiensi penyerapan dan pemanfaatan cahaya matahari yang sepanjang masa pertanaman oleh tajuk tanaman.

Menurut Goldsworthy dan Fisher (1992), berat kering tanaman tergantung pada pertumbuhan organ vegetatifnya. Berat kering akar tergantung pada jumlah fotosintat dan fotosintat yang dihasilkan dipengaruhi oleh suplai nutrisi dan air yang diperoleh tanaman. Pada kondisi tingkat kolonisasi FMA yang rendah dapat belum bisa menyuplai hara untuk meningkatkan fotosintesis terhadap tumbuhan sehingga belum memberikan pengaruh terhadap berat kering akar tanaman.

\section{Persentase Derajat Infeksi FMA pada Akar Tanaman Surian}

Persentase derajat infeksi akar bibit tanaman Surian yang diinokulasi dengan beberapa dosis FMA pada media tanah ultisol dengan campuran pupuk kompos menunjukkan kriteria sedang-tinggi. Kriteria infeksi FMA yang tinggi terjadi pada penambahan dosis $5 \mathrm{~g}$ dan $10 \mathrm{~g}$ dengan persentase sangat tinggi ditunjukan oleh perlakuan dosis $15 \mathrm{~g}$ sebesar 80\%. Hal ini diduga karena FMA mampu bekerjasama pada media tanam tanaman SURIAN. Pada perlakuan tanpa inokulasi juga terinfeksi FMA, hal ini menunjukkan bahwa FMA sudah ada pada tanah ultisol dengan penambahan pupuk organik. Menurut Delvian (2003), kelembapan tanah yang tinggi pada tanah yang basah akan merangsang perkecambahan spora dan terbentuknya kolonisasi dengan tanaman inang. Hal ini sesuai dengan hasil penelitian Triyanto (2008) bahwa terjadi infeksi FMA pada perlakuan tanpa inokulasi dengan kriteria rendah-sedang pada pertumbuhan bibit kelapa sawit. Contesa (2010) melaporkan pertumbuhan bibit tanaman pisang yang tidak diinokulasi dengan FMA menunjukkan adanya infeksi FMA dengan kriteria rendah. Dengan pemberian inokulan mikoriza ke dalam tanah maka akan semakin banyak akar-akar yang terinfeksi dan kemungkinan infeksi yang terjadi pada tanaman yang tidak diberi inokulan merupakan akibat dari infeksi mikoriza indigenous (Mosse, 1981).

Pada hasil penelitian (tertera pada Gambar 5), ditemukan beberapa struktur mikoriza dalam akar antara lain hifa dan 
vesikula. Adanya infeksi FMA yang tinggi pada perakaran tanaman menunjukkan bahwa adanya kecocokan antara FMA dengan tanaman inangnya (Smith \& David, 1997). Kecocokan antara FMA dengan tanaman inang juga dipengaruhi oleh jenis FMA yang digunakan. Menurut Subiksa (2002) faktor biotik yang mempengaruhi efektiftias mikoriza yaitu spesies FMA, kompetisi antar fungi mikoriza, tanaman inang dan tipe perakaran tanaman inang. Sedangkan derajat FMA yang tergolong sangat tinggi dimungkinkan karena adanya eksudat akar tanaman yang mampu mendukung pertumbuhan inokulan FMA dan kondisi tersebut menunjukkan bahwa asosiasi antara FMA dengan akar tanaman berkembang sangat baik. Eksudat akar mengandung karbohidrat, asam amino dan substansi lainnya yang dibutuhkan oleh FMA (Simarmata, 2005). Terjadinya asosiasi antara FMA dengan tanaman dapat diketahui dengan terinfeksi atau tidaknya akar tanaman. Infeksi FMA diketahui dengan adanya struktur-struktur yang dihasilkan oleh FMA antara lain yaitu: hifa, arbuskula, miselia. Adanya infeksi FMA yang tinggi pada perakaran tanaman menunjukkan bahwa adanya kecocokan antara FMA dengan tanaman inangnya (Smith \& David, 1997).

\section{KESIMPULAN}

Pemberian pupuk kompos dengan inokulasi beberapa dosis FMA pada media tanah ultisol memberikan pengaruh nyata terhadap pertambahan diameter batang bibit surian namun memberikan pengaruh tidak berbeda nyata pada tinggi dan jumlah daun.

\section{UCAPAN TERIMA KASIH}

Terima kasih penulis ucapkan kepada Prof. Dr. Dahelmi, Dr. Resti Rahayu, Suwirmen, MS dan Zuhri Syam, MP yang telah memberikan bimbingan, saran dan kritik dalam menyelesaikan artikel ini.

\section{REFERENSI}

Brundrett, N., Bougher, B., Dell, T., Grove, \& Malajazuk, N. (1996). Working with mycorrhizas in forestry and agriculture. Canberra: Australian Centre for International Agriculture Research.
Contesa, E. (2010). Pertumbuhan bibit tanaman pisang (Musa paradisiaca L.) FHIA-25. yang diinokulasi dengan beberapa dosis FMA Glomus sp. + Acaulospora sp. (Skripsi). Biologi FMIPA. Universitas Andalas, Padang.

Delvian. (2003). Keanekaragaman cendawan mikoriza arbuskula di hutan pantai dan potensi pemanfaatannya: Studi di hutan Cagar Alam Leuweung Sancang, Kecamatan Pameungpeuk Kabupaten Garut, Jawa Barat. (Disertasi). Program Pasca Sarjana Institut Pertanian Bogor, Bogor.

Durahim \& Hendromono. (2001). Kemungkinan Penggunaan Limbah Organik Sabut Kelapa Sawit dan Sekam Padi Sebagai Campuran Top Soil untuk Media Pertumbuhan Bibit Mahoni (Swictenia macrophylla King). Buletin Penelitian Hutan, 628, 13-26.

Farida, A. (1995). Pertumbuhan dan hasil tanaman tomat (Lycopersium esculentum. Mill) dengan perlakuan mikoriza vesikula arbuskula (MVA) dan pupuk organik kascing pada tanah ultisol. 65.

Goldsworthy, P. R., \& Fisher, N. M. (1992). Fisiologi tanaman budidaya tropik. Yogyakarta: Universitas Gadjah Mada Press.

Herdina, J. (2013). Pertumbuhan beberapa tanaman untuk revegetasi yang diinokulasi ektomikoriza pada lahan bekas tambang batu bara Ombilin. (Tesis). Pascasarjana Universiatas Andalas, Padang.

Khaerudin. (1999). Pembibitan tanaman HTI. Jakarta: Penebar Swadaya.

Mosse, B. (1981). Vesicular arbuscular mycorrhizal research for tropical agriculture. Research Bulletin 194. Hawaii Institute of Tropical Agriculture and Human Resources. University of Hawaii.

Kononova, M. M. (1966). Soil organic matter. Second Edition. Oxford: Pergamon Press Ltd.

Omon, R. M. (2008). Pengaruh dosis tablet terhadap pertumbuhan dua jenis meranti merah asal benih dan stek di HPH PT. ICHIKU, Balikpapan, Kaltim. 
Kalimantan Tengah: Balai Penelitian Teknologi Pembenihan Samboja.

Prawirawinata, W., Harran, S., \& Tjondronegoro, P. (1995). Dasar-dasar fisiologi tumbuhan. Jilid II. Bogor: Departemen Botani Fakultas MIPA IPB.

Samsudi (1990). Mengharap peningkatan produksi kayu dari hutan alam. Majalah Silvika. III(15). Bogor: Pusat Diklat Pegawai Kehutanan Departemen Kehutanan.

Sarief, E. S. (1985). Kesuburan dan pemupukan tanah pertanian. Bandung: Pustaka Buana.

Simarmata, T. (2005). Revitalitasi kesehatan ekosistem lahan kritis dengan pemanfaatan pupuk biologis mikoriza dalam percepatan pengembangan pertanian ekologis di indonesia. Prosiding Seminar Nasional dan Workshop Pemanfaatan Cendawan Mikoriza untuk Meningkatkan Produksi Tanaman pada Lahan Marginal. Jambi: Asosiasi Mikoriza Indonesia.

Smith, S. E., \& David, J. R. (1997). Mycorrhizal symbiosis. Second Edition. London: Academic Press.

Soepardi, G. (1983). Sifat dan ciri tanah. Bogor: Fakultas Pertanian Insitut Pertanian Bogor.
Subiksa, I. G. M. (2002). Pemanfatan mikoriza untuk penanggulangan lahan kritis. (Makalah Falsafah Sains). Pascasarjana Institut Pertanian Bogor, Bogor.

Suntoro. (2001). Pengaruh residu penggunaan bahan organik, dolomit dan $\mathrm{KCl}$ pada tanaman kacang tanah (Arachis Hypogeae. L.) pada oxic dystrudept di Jumapolo, Karanganyar. Habitat, 12(3), 170-177.

Tirta, I. G. (2006). Pengaruh kalium dan mikoriza terhadap pertumbuhan bibit panili (Vanilla planifolia Andrew). Biodiversitas, 7(2), 171-174.

Triyanto. (2008). Pemberian bokashi terhadap pertumbuhan bibit kelapa sawit (Elaeis giuneensis Jacq.) yang diinokulasi dengan cendawan mikoriza arbuskula (CMA). (Skripsi). Biologi FMIPA Universitas Andalas, Padang.

Yuhernita \& Juniarti. (2009). Skrining awal bioaktivitas daun surian [Toona sureni (B1.) Merr.] dengan metoda brine shrimp lethality test (BSLT) dan perendaman 2,2-diphenyl-1-picrylhy-drazyl (DPPH). Jurnal Kimia Mulawarman, 6(2), 33-36. 